\title{
I mpact of adding distal forearm DXA to hip and spine measurements on DXA report
}

\author{
Maseeh Uz Zaman ${ }^{1}$, Nosheen Fatima², Zafar Sajjad ${ }^{1}$, Zohra Pirwani ${ }^{1}$ \\ 1. Department of Radiology, The Aga Khan University Hospital (AKUH), Karachi, Pakistan. 2. Department of Nuclear \\ Medicine, Dr. Ziauddin Medical University, Karachi, Pakistan.
}

Correspondence: Dr. Maseeh Uz Zaman. Address: Department of Radiology, The Aga Khan University Hospital (AKUH), Stadium Road, Karachi, Pakistan. Email: maseeh.uzzaman@aku.edu.

Received: December 5, 2012

Accepted: March 10, $2013 \quad$ Online Published: April 23, 2013

DOI : $10.5430 /$ jbgc.v3n3p63

URL: http://dx.doi.org/10.5430/jbgc.v3n3p63

\begin{abstract}
Dual energy X-ray absorptiometry (DXA) is the gold standard modality for non-invasive diagnosis of osteoporosis but controversy exists about the optimal site (s) for bone mineral density (BMD) measurement. The objective was to find out impact of adding distal forearm BMD to hip and spine measurements on final diagnosis of a DXA study. This prospective study recruited 279 consecutive patients [female $256(92 \%)$; male $23(8 \%)$ ] with a mean age of $63.25 \pm 10.62$ years from April 2011 to April 2012. The BMD was measured over hip (total hip and femoral neck), spine and distal forearm in all patients. Based on T-Score values of hip and spine ( 2 sites), diagnosis was normal in 34\%, low bone mass in $40 \%$ and osteoporosis in 26\% patients. However, adding distal forearm BMD and T-score (3 sites), diagnosis was normal in 28\%, low bone mass in 37\% and osteoporosis in 35\%. Therefore, distal forearm BMD has upstaged the diagnosis from normal to low bone mass in $14 \%$, from normal to osteoporosis in $2 \%$ and from low bone mass to osteoporosis in $18 \%$ patients. We conclude that combining distal forearm BMD with spine and hip can identify more patients with low bone mass or osteoporosis.
\end{abstract}

\section{Key words}

Dual energy X-ray absorptiometry, Bone mineral density, Distal forearm, Upstaging, Osteoporosis, Low bone mass

\section{I ntroduction}

Osteoporosis is a common condition associated with an increased risk of fracture, morbidity, and mortality ${ }^{[1]}$. Measurement of bone mineral density (BMD) using dual energy X-ray absorptiometry (DXA) is the "gold-standard" method for the noninvasive diagnosis of osteoporosis ${ }^{[2,3]}$. The World Health Organization (WHO) criterion for the diagnosis osteoporosis is based on T-score which is number of standard deviation (SD) values that the measured BMD of the hip, lumbar spine, or distal 1/3rd forearm varies from the mean BMD of a young-adult reference population ${ }^{[4]}$. According to International Society for Clinical Densitometry (ISCD) official position statement, BMD is measured at lumbar spine (posterior -anterior view; PA) and hip in all patients and over non-dominant forearm (distal 1/3rd) BMD when hip and/or spine cannot be measured or interpreted, in cases of hyperparathyroidism, or in very obese patients (beyond the weight limit for DXA table) ${ }^{[5]}$. Studies have shown that DXA of distal forearm to be a good predictor of osteoporotic fractures, both at the spine and the hip ${ }^{[6,7]}$. Most of the centers around the world measure BMD at two sites 
(hip and spine) with inclusion of distal forearm in special circumstances as per ISCD guidelines ${ }^{[5]}$. However, certain centers routinely measure BMD at 3 sites with a premise that inclusion of distal forearm BMD, results in upstaging in the final diagnosis in small but significant percentage of studies ${ }^{[8]}$.

The objective of this study was to find out impact of adding distal forearm BMD to hip and spine measurements on final diagnosis of a DXA study.

\section{Material and methods}

This is a prospective study conducted at department of radiology, Aga Khan University Hospital, Karachi, Pakistan from April 2011 to April 2012. We recruited 279 consecutive patients who were referred for BMD estimation by DXA over hip, spine and distal forearm. Patients with history of primary hyperparathyroidism were excluded from the study. Patients were advised to stop their calcium supplement 24 hour prior the test. Patients who had oral or intravenous contrast based radiological examination or nuclear medicine procedure, DXA study was deferred for 6-10 days to avoid erroneous values. BMD of hip (left hip or right hip in case of severe arthritis or implant over left side), spine (L1-4) and non-dominant forearm as per ISCD recommendations ${ }^{[5]}$ was estimated using Discovery A, Hologic, USA. BMD and T scores over total hip, femoral neck, lumbar spine and distal forearm were used for analysis.

According to WHO recommendation, diagnosis was made on basis of lowest $\mathrm{T}$ score at any measured site (T score $\geq-1 \mathrm{SD}$ $=$ Normal; $\mathrm{T}$ score between -1 and $-2.5 \mathrm{SD}=$ Low bone mass, and $\mathrm{T}$ Score $\leq-2.5 \mathrm{SD}=$ Osteoporosis).

Data was analyzed by using commercially available packages the Medcalc ${ }^{\circledR}$ statistical software version 11.3 .10 and statistical package for social sciences (SPSS version 17®). Comparisons between patient groups were performed using Student's $t$ test for continuous variables (null hypothesis that a sample mean is equal to a given mean with unknown standard deviation or certified value) and the Chi-square $\left(\chi^{2}\right)$ test for categorical variables. Continuous variables were described by mean \pm standard deviation (SD). For all P-values $<0.05$ were selected as significant.

\section{Results}

We recruited 279 patients [female $256(92 \%)$; male $23(8 \%)$ ] with a mean age of $63.25 \pm 10.62$ years (range 26-91 years). The lowest mean BMD and mean T scores were found at distal forearm (BMD: $0.471 \pm 0.080$ : range 0.242 - 0.698 ; $\mathrm{T}$ score: $-2.004 \pm 1.635$ : range $-6.3-2.3$, significant $p$ value). The highest mean BMD and mean $\mathrm{T}$ scores were found at spine (BMD: $0.896 \pm 0.228$ : range $0.228-1.810$; T Sore: $-1.257 \pm 1.635$ : range $-5.4-5.4$, significant $p$ value). Mean BMD and $\mathrm{T}$ scores of total hip and femoral neck were between two limits over distal forearm and spine (see Table 1).

By considering the distal forearm BMD as an independent and comparing with other variable (as hypothesized as dependant variables) it was found significantly low as compared with spine, total hip and femoral neck although with smaller scattered values i.e. smaller SD (see Table 2). In normal (T score $\geq 1 \mathrm{SD}$ as per WHO criteria) and abnormal DXA studies (T score $<1 \mathrm{SD}$ as per WHO criteria) [3 sites], statistically significant highest mean BMD was found over lumbar spine followed by total hip, femoral neck and the lowest over distal forearm (see Table 3).

Based on T-Score values of hip and spine ( 2 sites), diagnosis was normal in 34\%, low bone mass in $40 \%$ and osteoporosis in $26 \%$ patients. However, adding distal forearm BMD and T-score (3 sites), the diagnosis was normal in $28 \%$, low bone mass in 37\% and osteoporosis in 35\% (see Figure 1). Therefore, distal forearm BMD has upstaged the diagnosis from normal to low bone mass in $14 \%$, from normal to osteoporosis in $2 \%$ and from low bone mass to osteoporosis in $18 \%$ patients (see Figure 2). 
Table 1. Patients' demographics

\begin{tabular}{|c|c|c|c|c|}
\hline \multirow{2}{*}{ Variables } & \multirow{2}{*}{ Total population (279) } & \multicolumn{2}{|l|}{ Range } & \multirow{2}{*}{$p$ value } \\
\hline & & Lowest & Highest & \\
\hline Age $($ mean \pm SD) years & $63.25 \pm 10.62$ & 26 years & 91 years & $<0.0001^{*}$ \\
\hline \multicolumn{5}{|l|}{ Gender } \\
\hline Female: Male & 256: 23 (92\%: 8\%) & ---- & & $<0.0001^{*}$ \\
\hline \multicolumn{5}{|l|}{ Total hip } \\
\hline $\mathrm{BMD}($ mean $\pm \mathrm{SD})$ & $0.811 \pm 0.150$ & 0.360 & 1.244 & \multirow{2}{*}{$<0.0001 *$} \\
\hline $\mathrm{T}$ score $($ mean $\pm \mathrm{SD})$ & $-1.909 \pm 1.22$ & -4.8 & 2.5 & \\
\hline \multicolumn{5}{|l|}{ Femoral neck } \\
\hline $\mathrm{BMD}($ mean $\pm \mathrm{SD})$ & $0.672 \pm 0.151$ & 0.303 & 1.106 & \multirow{2}{*}{$<0.0001 *$} \\
\hline T score (mean \pm SD) & $-1.564 \pm 1.151$ & -4.9 & 1.3 & \\
\hline \multicolumn{5}{|l|}{ Spine } \\
\hline $\mathrm{BMD}($ mean $\pm \mathrm{SD})$ & $0.896 \pm 0.228$ & 0.228 & 1.810 & \multirow{2}{*}{$<0.0001^{*}$} \\
\hline $\mathrm{T}$ score $($ mean $\pm \mathrm{SD})$ & $-1.257 \pm 1.635$ & -5.4 & 5.4 & \\
\hline \multicolumn{5}{|l|}{ Distal forearm } \\
\hline $\mathrm{BMD}($ mean $\pm \mathrm{SD})$ & $0.471 \pm 0.080$ & 0.242 & 0.698 & \multirow{2}{*}{$<0.0001^{*}$} \\
\hline T score $($ mean \pm SD) & $-2.004 \pm 1.635$ & -6.3 & 2.3 & \\
\hline
\end{tabular}

Note. $\mathrm{SD}=$ Standard Deviation. $\mathrm{BMD}=$ Bone Mineral Densitometry. ${ }^{*} p<0.05$

Table 2. Comparative analysis of mean bone mineral densitometry of distal forearm with other sites.

\begin{tabular}{lll}
\hline Dependant variables & $\boldsymbol{t}$-test & $\boldsymbol{P}$ value \\
\hline Total Hip BMD Vs Distal Forearm BMD & -33.347 & $<0.0001^{*}$ \\
Femoral neck BMD Vs Distal Forearm BMD & -19.612 & $<0.0001^{*}$ \\
Spine BMD Vs Distal Forearm BMD & -29.327 & $<0.0001^{*}$ \\
\hline
\end{tabular}

Note. BMD=Bone Mineral Densitometry; ${ }^{*} p<0.05$

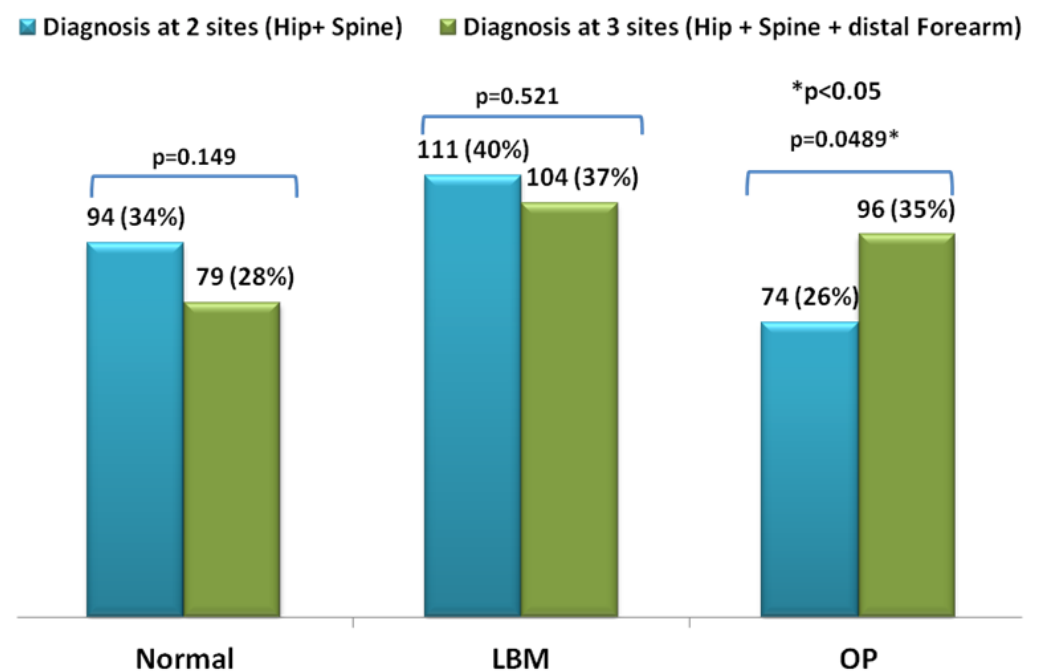

Figure 1. Overall change in diagnosis of dual energy X-ray absorptiometry at two sites of spine and hip values by adding distal forearm values. 




Figure 2. Upstaging in diagnosis of DXA report by adding distal foream to hip and spine BMD values.

Table 3. Comparison of bone mineral densitometry values in normal and abnormal findings.

\begin{tabular}{|c|c|c|c|c|c|}
\hline Variables & $\begin{array}{l}\text { BMD values of Normal } \\
\text { DXA (94) } \\
\text { (T score } \geq-1 S D) \\
\text { Mean } \pm \text { SD }\end{array}$ & $\begin{array}{l}\text { BMD values of Abnormal } \\
\text { DXA (185) } \\
\text { (T score }<-1 \text { SD) } \\
\text { Mean } \pm \text { SD }\end{array}$ & $t$-test & $\begin{array}{l}95 \% \text { Confidence } \\
\text { Interval }\end{array}$ & $p$ value \\
\hline Lumbar spine BMD & $1.018 \pm 0.177$ & $0.834 \pm 0.226$ & -6.890 & -0.2366 to- 0.1314 & $<0.0001^{*}$ \\
\hline Total hip BMD & $0.898 \pm 0.168$ & $0.767 \pm 0.119$ & -7.526 & -0.2366 to- 0.1314 & $<0.0001^{*}$ \\
\hline Femoral neck BMD & $0.751 \pm 0.148$ & $0.632 \pm 0.137$ & -6.673 & -0.1541 to- -0.08389 & $<0.0001 *$ \\
\hline $\begin{array}{l}\text { Distal Forearm } \\
\text { BMD }\end{array}$ & $0.499 \pm 0.090$ & $0.456 \pm 0.070$ & -4.392 & -0.1541 to- 0.08389 & $<0.0001^{*}$ \\
\hline
\end{tabular}

Note. $\mathrm{BMD}=$ Bone mineral densitometry. ${ }^{*} p<0.05$

\section{Discussion}

DXA is an established gold standard modality for non-invasive diagnosis of osteoporosis but controversy exists about the optimal site (s) for BMD measurement. Hip and lumbar spine are the two most commonly used sites but International Osteoporosis Foundation (IOF) recommends measurement at hip only ${ }^{[3]}$ while ISCD recommends measurement at hip and spine in all and distal forearm in special circumstances ${ }^{[5]}$. In this study we have measured BMD at all three sites as in osteoporosis rate of bone loss varies according to the patient's age and skeletal site and studies have shown that using only one site like whole body BMD ${ }^{[9]}$ or hip only may lead to false negative results of DXA reports ${ }^{[10]}$. Furthermore, reports have shown positive association between number of osteoporotic sites and fracture risk ${ }^{[1]]}$. However, a large metaanalysis revealed that using the minimum site for fracture risk assessment was no better than using a single site ${ }^{[12]}$.

In this study, the spine has the highest BMD values followed by hip and distal forearm in patients with normal and abnormal studies. This is usual pattern with a reported $10 \%-15 \%$ annual fall over these sites in normal women ${ }^{[13]}$. Similarly, lower or higher BMD values over distal forearm were found to be a good predictor of presence or absence of osteoporosis at femoral neck and spine respectively ${ }^{[7]}$.

Most important outcome of this study is the impact of distal forearm DXA in upstaging the diagnosis from normal to abnormal or from low bone mass to osteoporosis in a significant number of patients. This means that using 2 sites (spine and hip) in these patients would have underestimated or missed the diagnosis of either low bone mass or osteoporosis. This is in accordance with a recently published study on patients with primary hyperparathyroidism in which worst BMD values were found at distal forearm with upstaging in diagnosis to low bone mass or osteoporosis in $9.4 \%$ of patients ${ }^{[8]}$. 
The greater impact of distal forearm DXA in our study might be due to smaller scatter (small $\pm \mathrm{SD}$ ) of BMD as compared with spine and hip and a subtle change in distal forearm BMD should have an exponential change in $\mathrm{T}$ score. This is the reason for higher upstaging from normal to low bone mass and from low bone mass to osteoporosis and little impact on upstaging normal to osteoporosis. Implication of adding distal forearm DXA results in a better diagnostic accuracy in a significant number of patients, timely treatment which lowers the risk of fracture, associated morbidity and immense financial burden. We cannot neglect the additional but avoidable radiation exposure by adding distal forearm in a standard DXA study. Radiation dose to patient from a DXA of distal forearm delivers 0.1 micro Sievert (uSv) which is a trivial dose and much below the natural background (in United Kingdom natural background radiation exposure is $7 \mathrm{uSv} / \mathrm{d}$ ) ${ }^{[14]}$. However, one cannot deny that implication of missing or under-diagnosing the osteoporosis would be exorbitant which could be avoided at the cost of trivial radiation dose to patient. We did not follow these patients for the treatment on the basis of their DXA findings and complications which is a limitation of the study indeed. Another limitation of this study is female predominance in the study cohort which is the usual referral pattern in our clinical practice. This study also draws our attention toward the importance of standardization of measuring sites for DXA which needs a consensus among the major stakeholders.

We conclude that BMD over distal forearm is significantly low as compared with hip and spine and inclusion of distal forearm DXA to spine and hip measurements can identify more patients with low bone mass or osteoporosis.

\section{References}

[1] Cooper C, Atkinson EJ, Jacobsen SJ, et al. Population based study of survival after osteoporotic fractures. Am J Epidemiol. 1993; 137(9): 1001-1105.

[2] Delmas PD. Do we need to change the WHO definition of osteoporosis? Osteoporos Int. 2000; 11: 189-191. PMid:10824233 http://dx.doi.org/10.1007/s001980050280

[3] Kanis JA, Gluer CC. An update on the diagnosis and assessment of osteoporosis with densitometry. Committee of Scientific Advisors, International Osteoporosis Foundation. Osteoporos Int. 2000; 11: 192-202. PMid:10824234 http://dx.doi.org/10.1007/s001980050281

[4] Kanis JA. Assessment of fracture risk and its application to screening for postmenopausal osteoporosis: synopsis of a WHO report. WHO Study Group. Osteoporos Int. 1994; 4: 368-381. PMid:7696835 http://dx.doi.org/10.1007/BF01622200

[5] Lewiecki EM, Watts MB, McLung MR, et al. Official Positions of the International Society for Clinical Densitometry. J Clin Endocrinol Metab. 2004; 89: 3651-3655. PMid:15292281 http://dx.doi.org/10.1210/jc.2004-0124

[6] Duppe H, Gardsell P, Nilsson B, Johnell O. A single bone density measurement can predict fractures over 25 years. Calcifi Tissue Int. 1997; 60: 171-174. PMid:9056166 http://dx.doi.org/10.1007/s002239900209

[7] Jones T, Davie MW. Bone mineral density at distal forearm can identify patients with osteoporosis at spine or femoral neck. Br J Rheumatol. 1998; 37: 539-543. PMid:9651082 http://dx.doi.org/10.1093/rheumatology/37.5.539

[8] Wood K, Dhital S, chen H, Sippel RS. What is utility of distal forearm DXA in primary hyperthyroidism? The Oncologist. 2012; 17: 322-325. PMid:22258698 http://dx.doi.org/10.1634/theoncologist.2011-0285

[9] Lidwien GV, Martijn AS, Ben EEMB, Frank WJMS, Emiel FMW. Whole-Body versus Local DXA-Scan for the Diagnosis of Osteoporosis in COPD Patients, Journal of Osteoporosis. 2010, Article ID 640878, 6 pages, 2010. http://dx.doi.org/10.4061/2010/640878

[10] Asma A, Rafic B, Hassane A, et al. Discriminative ability of dual-energy X-ray absorptiometry site selection inidentifying patients with osteoporotic fractures. Bone. 2007; 40: 1060-1065. PMid:17223616 http://dx.doi.org/10.1016/j.bone.2006.11.017

[11] Leslie WD, Tsang JF, Caetano PA, Lix LM. Number of Osteoporotic Sites and Fracture Risk Assessment: A Cohort Study From the Manitoba Bone Density Program. J Bone Miner Res. 2007; 22: 476-483. PMid:17144788 http://dx.doi.org/10.1359/jbmr.061112

[12] Kanis JA, Johnell O, Oden A, et al. The use of multiple sites for the diagnosis of osteoporosis. Osteoporos Int. $2006 ; 17: 527-534$. PMid:16402164 http://dx.doi.org/10.1007/s00198-005-0014-9

[13] Ryan PJ, Blake GM, Fogelman I. Measurement of forearm bone mineral density in normal women by dual-energy X-ray absorptiometr. The British Journal of Radiology. 1991; 65: 127-131. http://dx.doi.org/10.1259/0007-1285-65-770-127

[14] Patel R, Blake GM, Fogelman I. Radiation Dose to the Patient and Operator from a Peripheral Dual X-Ray Absorptiometry System. Journal of Clinical Densitometry. 1999; 2: 397-401. http://dx.doi.org/10.1016/S1094-6950(06)60405-8 